\title{
Fasting Plasma Total Amino Acid Levels in Relation to Glucose Levels in Type 2 Diabetes Mellitus - A Study from Karnataka, India
}

\author{
Mohammed Ali Musaraza K.S. ${ }^{1}$, Lata R. Telang², Kashinath Ratti Halli Thirumalarao³ \\ 1, 3 Department of Research and Development, Subbaiah Institute of Medical \\ Sciences(SUIMS), Purle, Shivamogga, Karnataka, India, ${ }^{2}$ Subbaiah Research Center, \\ SUIMS Campus, Purle, Shivamogga, Karnataka, India.
}

\section{ABSTRACT}

\section{BACKGROUND}

Hyperglycemia, observed in type 2 diabetus mellites (T2DM) patients, is the primary root cause for the development of life threatening - diabetes induced micro- \& macrovascular complications. Generally, in fasting state, gluconeogenesis accounts for about $30 \%$ of overall hepatic glucose output and the increase in type 2 diabetic subjects may be much more than this level. The majority of gluconeogenic precursors may originate from muscle glycolysis and in the form of glucogenic amino acids including alanine. We wanted to assess fasting plasma total amino acid levels in T2DM patients and correlate the levels with the glycaemic status of T2DM patients in this study.

\section{METHODS}

The observational comparative study was undertaken at Research and Development department, from October 2019 to November 2020 and it consisted of 157 subjects, including 75 normal control subjects, and 82 T2DM patients. The T2 diabetic patients attending medical OPD of Subbaiah Institute of Medical Sciences, Purle, Shivamogga (SUIMS) were randomly selected and were sub-grouped in to 3 groups depending on their fasting plasma glucose (FPG) levels. The group 1 patients were having FPG level in the range of $150-200 \mathrm{mg} / \mathrm{dl}$, group 2 patients having in the range of $201-250 \mathrm{mg} / \mathrm{dl}$ and the group 3 patients were having FPG above $251 \mathrm{mg}$ / dl.

\section{RESULTS}

It is evident from the present study that FPG levels as well as AAN levels are significantly $(\mathrm{P}>0.001)$ elevated in T2DM patients as compared to normal control subjects and there is a proportional rise in AAN levels in relation to FPG Levels in T2dm patients.

\section{CONCLUSIONS}

The rise in plasma AN levels is proportional to glycemic status in T2DM patients and can be employed to assess the glycemic status in these patients.

\section{KEY WORDS}

Amino Acids, Gluconeogenesis, Type 2 Diabetes Mellitus
Corresponding Author: Dr. Kashinath R.T., Research and Development Department, Subbaiah Institute of Medical Sciences, Purle, Shivamogga, Karnataka, India. E-mail: drkashinath_1945@yahoo.co.in

DOI: $10.14260 /$ jemds/2021/376

How to Cite This Article: Musaraza KSMA, Telang LR,Thirumalarao KRH. Fasting plasma total amino acid levels in relation to glucose levels in type 2 diabetes mellitus - a study from Karnataka, India. $J$ Evolution Med Dent Sci 2021;10(24):1819-1824, DOI: 10.14260/jemds/2021/376

Submission 05-02-2021,

Peer Review 19-04-2021,

Acceptance 26-04-2021,

Published 14-06-2021.

Copyright (C) 2021 Mohammed Ali Musaraza K.S. et al. This is an open access article distributed under Creative Commons Attribution License [Attribution 4.0 International (CC BY 4.0)] 


\section{BACKGROUND}

Hyperglycemia, observed in type 2 diabetes mellitus (T2DM) patients, is the root-cause for the development of life threatening - diabetes induced micro- \& macro-vascular complications, ${ }^{1,2}$ like retinopathy, nephropathy, cardiopathy and neuropathy. A prompt regulation of blood glucose level is very much essential to abolish or to delay the onset of these complications. One of the prominent endogenous contributor of blood glucose is gluconeogenesis, the process of formation of glucose from non-carbohydrate metabolites which is generally increased in diabetes mellitus mainly due to deficiency of insulin - sole hypoglycemic hormone, as insulin is a known gluconeogenic suppressor. ${ }^{3}$ Among the various glucogenic metabolites glucogenic amino acids are significant.

Insulin, apart from facilitating the glucose transport across the cell membranes as well as increasing glucose utilisation by cells, is also known to suppress tissue proteolysis, ${ }^{4-6}$ a prime source of free amino acids which may be utilized for gluconeogenesis. The deficiency of insulin as observed in T2DM patients may cause unsuppressed proteolysis which provides significant amount of glucogenic amino acids hence facilitating increased formation of glucose through gluconeogenesis. The rise in plasma amino acid levels has been observed by many researchers ${ }^{7-11}$ and the rise specifically in branched-chain amino acid levels has been noted by few earlier workers. ${ }^{12-14}$ whereas few others have observed a significant fall in serum total amino acids in T2DM patients. ${ }^{15,16}$

\section{Objectives}

1. To estimate fasting plasma glucose and total amino acid levels in T2DM patients.

2. To correlate total amino acids levels with the glycaemic status of T2DM patients.

\section{METHODS}

The observational comparative study, involving the T2DM patients attending medical outpatient department (OPD) of Subbaiah Institute of Medical Sciences (SUIMS), Shivamogga and its affiliated hospitals, in the age group of $30-55$ years were randomly selected. A detailed history regarding the illness was collected from these patients. Normal control subjects in the age group of 30 - 55 years were taken from the employees of SUIMS and its affiliated hospitals, Shivamogga.

Diabetic patients below the age of 30 years and above 55 years, those with psychiatric disorders as well as the patients receiving hormone therapy were excluded from the study.

The present work was undertaken at Research and development department, SUIMS from October 2019 to November 2020 and the study consisted of 157 subjects, including 75 normal control subjects and 82 T2DM patients. These details are narrated in Chart 1.

A fasting heparanized blood sample (5 - $6 \mathrm{ml}$ ) was collected from both T2DM patients and from normal control subjects after obtaining a written informed consent from each one of them. The samples were centrifuged at $3000 \mathrm{rpm}$ for 6 - $8 \mathrm{~min}$ and the separated plasma was employed for the estimation of FPG $^{17}$ and plasma total amino acid nitrogen
$(\mathrm{AAN})^{18}$ levels.

\section{Glucose Estimation}

Plasma glucose was estimated by GOD - POD procedure. ${ }^{17}$ The hydrogen peroxide liberated upon oxidation of glucose by glucose oxidase was acted upon in site by peroxidase and the produced nascent oxygen converted anisidine to give quantitatively a coloured complex which was measured photometrically.

\section{AAN Estimation}

The amino acids present in tungstate protein free filtrate of plasma were determined by Folin method. ${ }^{18}$ using 1 - Amino, - 2 - naphthalo - 4 - sulphonic acid and the greenish coloured complex produced was measured photometrically at the type 2 diabetic patients who were sub-grouped in to 3 groups depending on their fasting plasma glucose (FPG) levels. The group 1 patients were having FPG levels in the range of 150 $200 \mathrm{mg} / \mathrm{dl}$, group 2 patients in the range of $201-250 \mathrm{mg} / \mathrm{dl}$ and the group 3 patients were having FPG above $251 \mathrm{mg} / \mathrm{dl}$.

\section{Statistical Analysis}

The data obtained was statistically analyzed using SPSS version 16 software. Student's t-test was used to ascertain the significance and the $P$ value less than 0.05 was considered statistically significant.

\section{RESULTS}

\begin{tabular}{|cc|}
\hline Group & FPG mg / dl \\
Group1 (26) & $150-200$ \\
Group 2 (28) & $201-250$ \\
Group 3 ( 28) & $<251$ \\
\hline Table 1. Distribution of T2DM Patients \\
According to Their FPG Levels \\
\hline Note - The number in parentheses indicates the number of patients. \\
\hline
\end{tabular}

\begin{tabular}{|c|c|c|}
\hline & FPG mg / dl & AAN \\
\hline Normal Controls ( 75 ) & $90.15 \pm 13.80$ & $6.75 \pm 1.66$ \\
\hline T2DM Patients ( 82 ) & $207.95^{* * *} \pm 36.80$ & $16.52^{* * *} \pm 4.72$ \\
\hline \multicolumn{3}{|c|}{$\begin{array}{c}\text { Table 2. Plasma Levels of Fasting Glucose (FPG), } \\
\text { and Total Amino Acid Nitrogen (AAN), in Normal } \\
\text { Control Subjects as Well as in T2DM Patients }\end{array}$} \\
\hline \multicolumn{3}{|c|}{$\begin{array}{l}\text { Note } \\
\text { 1. The values are expressed as their Mean } \pm \text { SD. } \\
\text { 2. The number in parentheses indicates the number of subjects. } \\
\text { 3. } \quad \text { Probability } * \mathrm{P}>0.05,{ }^{* *} \mathrm{P}>0.01 \text { and }{ }^{* * *} \mathrm{P}>0.001 .\end{array}$} \\
\hline
\end{tabular}

\begin{tabular}{|c|c|c|}
\hline T2 DM Sub - Groups & FPG Mg/dl & AAN \\
\hline $\begin{array}{c}\text { Group } 1 \\
(\mathrm{FPG}-150-200 \mathrm{mg} / \mathrm{dl})(26)\end{array}$ & $181.14 \pm 22.50$ & $8.55 \pm 1.20$ \\
\hline $\begin{array}{c}\text { Group } 2 \\
(\mathrm{FPG}-201-250 \mathrm{mg} / \mathrm{dl})(28)\end{array}$ & $\begin{array}{c}228.60^{* *} \pm \\
18.80\end{array}$ & $11.54^{* * *} \pm 1.80$ \\
\hline $\begin{array}{c}\text { Group } 3 \\
\text { (FPG - Above } 251 \mathrm{mg} / \mathrm{dl})(28) \\
\end{array}$ & $\begin{array}{l}260.72^{* *} \pm \\
28.80\end{array}$ & $12.14^{* *} \pm 1.75$ \\
\hline \multicolumn{3}{|c|}{$\begin{array}{l}\text { Table 3. Plasma Levels of FPG, and AAN, in } \\
\text { T2DM Patients Sub-Groups (Group 1, Group } 2 \text { and Group 3) }\end{array}$} \\
\hline 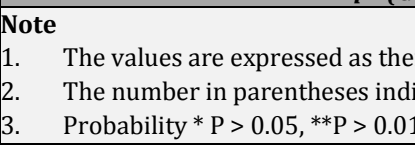 & $\begin{array}{l}\text { an } \pm \text { SD. } \\
\text { the number of } s t \\
{ }^{* * *} \mathrm{P}>0.001\end{array}$ & ubjects. \\
\hline
\end{tabular}

The results obtained in the present study are depicted in Table 1 and Table 2. Table 1 shows the level of FPG and AAN in normal control subjects as well as in T2DM patients. It is 
evident from the table that FPG levels as well as AAN levels are significantly $(\mathrm{P}>0.001)$ elevated in T2DM patients as compared to normal control subjects suggesting a close relationship between FPG levels and AAN levels in these T2DM patients. Table 2 depicts AAN level in group 1, group 2 and in group 3 T2DM patients. It is seen from the table that there is a proportionate rise in AAN levels in relation to FPG levels suggesting that amino acids maybe the principle contributors for glucose rise in these diabetic patients.

Figure $1 \mathrm{a}, 1 \mathrm{~b}$ and $1 \mathrm{c}$ shows the comparative variation graphs of TAA and FPG levels in Group 1, Group 2 and Group 3 T2DM patients. It is clear from the graphs that there is a direct relationship between FPG levels and plasma TAA levels suggesting that TAA levels may be related to the glycemic condition of a T2DM patient as well as an indicator of glycemic status in these patients.
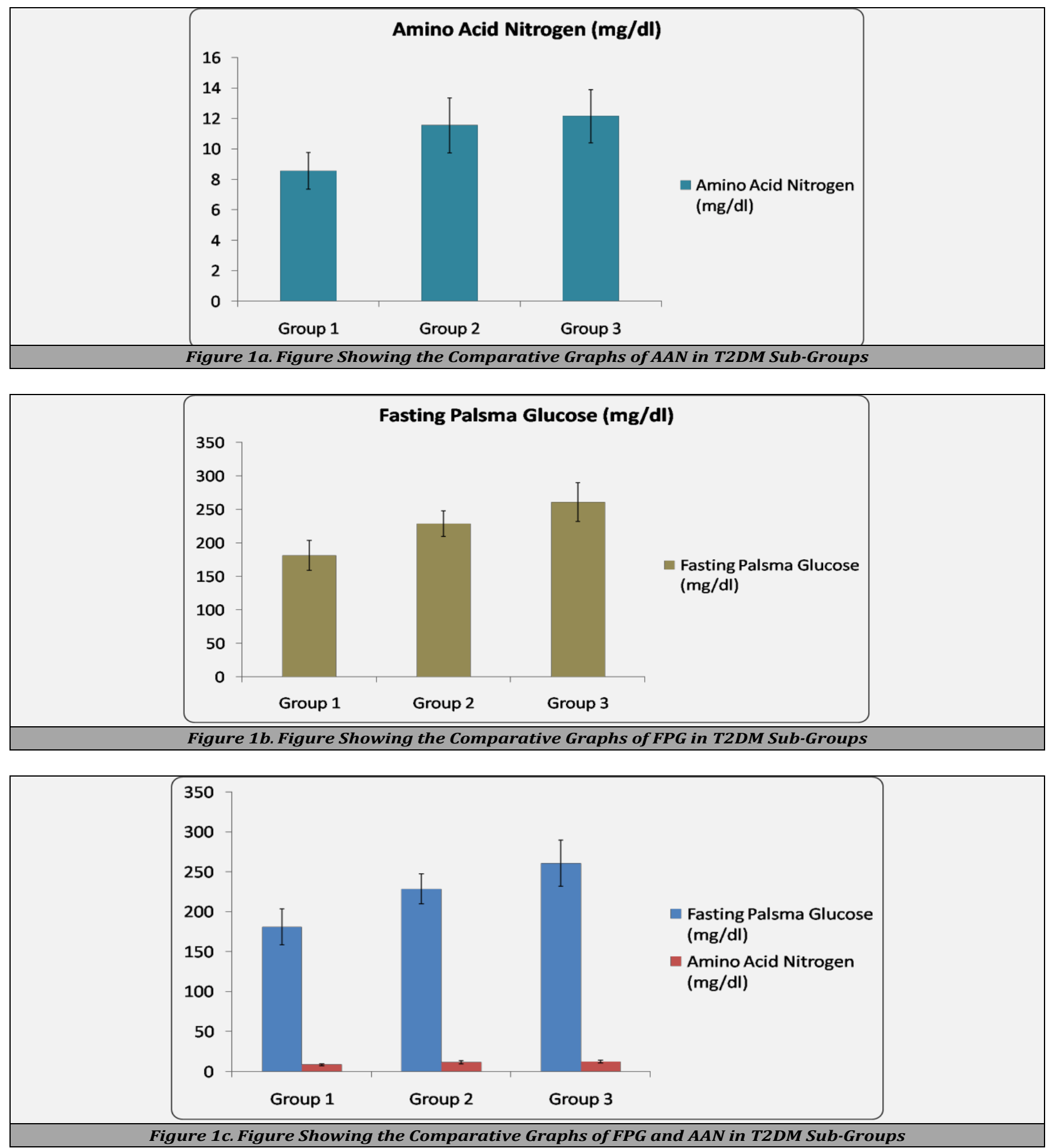

\section{DISCUSSION}

The circulating amino acids, which are related to insulin action through their tissue proteolysis suppression effect, may serve as novel biomarkers for predicting the risk of diabetic complications that may enlighten hitherto unknown pathways of diabetic pathophysiology $7,19,20$ as well as may explain the link between amino acids and the 
gluconeogenesis. Insulin, the lone hypoglycaemic hormone is known to influence many cellular metabolic reactions including gluconeogenesis, tissue proteolysis and tissue lipolysis through regulating the key enzymes involved in these pathways. The chart shown in Figure 2 clearly explains many significant actions of insulin, gluconeogenesis being the most significant among them.

Generally, in fasting state, gluconeogenesis accounts for about $30 \%$ of overall hepatic glucose output. ${ }^{19-24}$ and the increase in type 2 diabetic subjects may be much more than this level.25,26 The majority of gluconeogenic precursors may originate from muscle glycolysis and in the form of glucogenic amino acids including alanine. ${ }^{24}$ Apart from pyruvate and lactate, the amino acids are the significant gluconeogenic precursors and contribute to blood glucose levels in fasting as well as in diabetic state. It has been observed in our earlier studies that in alloxan diabetic rats the plasma as well as the liver tissue amino acids were significantly elevated which may be due to sub normal functions of insulin as insulin has a suppression effect on tissue proteolysis. This unsuppressed proteolysis in diabetic state supplies amino acids for endogenous glucose formation which is again favoured by subnormal insulin action as hormone insulin is the lone suppressor of the process gluconeogenesis.

In the present study it has been observed that there is a significant rise in plasma AAN levels in type 2 diabetic subjects which is in line with the observation made by earlier workers, ${ }^{27-29}$ suggesting a close relationship between glucose metabolism and amino acid metabolism which may be established through transamination reactions.
The key amino acid keto acid pairs involved in transamination reactions are glutamate- $\alpha$ - ketoglutarate, aspartate-oxaloacetate and pyruvate - alanine. Insulin, not only decreases the formation of glucose through gluconeogenesis by suppressing the activities of key gluconeogenic enzymes but also suppresses the tissue proteolysis $^{4-6}$ thereby decreasing the availability of amino acids for gluconeogenesis. Among the various glucogenic metabolites, glucogenic amino acids specifically alanine, aspartate and glutamate are significant.

Altered branched chain amino acid and aromatic amino acid levels have been reported in T2DM patients which may be due to an increased proteolysis because of sub normal insulin action. The glucogenic amino acids specifically alanine, aspartate and glutamate, derived from rised proteolysis maybe utilized as glucogenic precursors and the rest of the amino acids, branched chain and aromatic amino acids may show a rise in T2DM patients, hence the rise observed in the present study in plasma AAN substantiate the earlier findings. ${ }^{11,13,15,16,27}$

The glycemic status regulation, which is partly dependent on the hepatic glucose output through gluconeogenesis, is significant in T2DM patients in delaying the onset of diabetic complications.

It is evident from the table 2 and the graphs in Fig 1 that the glycemic status in group 1, group 2 and group 3 T2DM patients is proportional to plasma total amino acid levels suggesting a close relationship between glycemic status and plasma total amino acids in these patients (refer table $2 \&$ Figure 1).

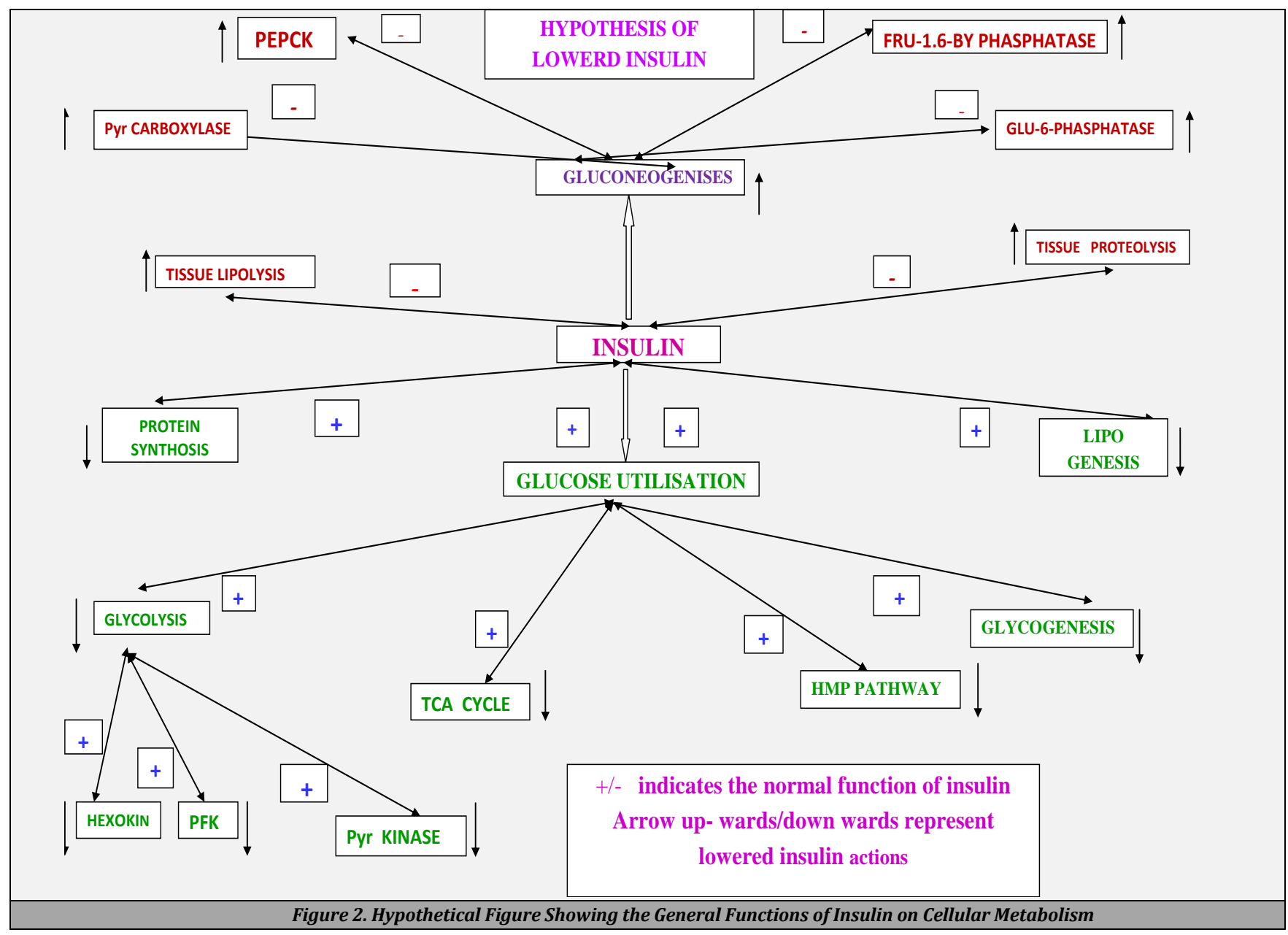


Further it has been shown by earlier workers that plasma total amino acids may predict the diabetic complications.12,14,29 resulting from uncontrolled hyperglycemia.

The present study establishes the fact that plasma total amino acids are significantly elevated in T2DM patients and this elevation is proportional to the glycemic status in these patients. Further the study establishes the need for development of agents which substantially lowers the tissue photolytic rate, the process which provide amino acids for gluconeogenesis, hence may result in regulation of glycemic status.

\section{CONCLUSIONS}

A significant rise in plasma AAN seen in T2DM patients may substantially contribute to the glycemic status of T2DM patients and may serve as an index to the gluconeogenic rate in these patients. The study also suggests a proper medication to br administered towards controlling or minimizing tissue proteolysis caused by insufficient action of insulin in these patients that may facilitate in achieving a prompt required glycaemic control.

Data sharing statement provided by the authors is available with the full text of this article at jemds.com.

Financial or other competing interests: None.

Disclosure forms provided by the authors are available with the full text of this article at jemds.com.

\section{REFERENCES}

[1] American Diabetes Association. Diagnosis and classification of diabetes mellitus. Diabetes Care 2010;33(Suppl 1):62-9.

[2] Fowler MJ. Microvascular and macrovascular complications of diabetes. Clinical Diabetes 2008;26(2):77-82.

[3] Dimitriadis G, Mitrou P, Lambadiari V, et al. Insulin effects in muscle and adipose tissue. Diabetes Res Clin Pract 2011;93(Suppl 1):S52-9.

[4] Fulks MR, Li JB, Goldberg AL. Effect of insulin, glucose and amino acids on protein turnover in rat diaphragm. J Biol Chem 1975;250(1):290-8.

[5] Jefferson LS, Rannels DE, Munger BL, et al. Insulin in the regulation of protein turnover in the heart and skeletal muscle. Fed Proc 1974;33(4):1098-104.

[6] Loundholm K, Edstrom S, Ekman L, et al. Prote indegradation in humanskeletal muscle tissue, the effect of insulin, leucine, amino acid, ions. Clin Sci (Lond) 1981;60(3):319-26.

[7] Guasch-Ferré M, Hruby A, Toledo E, et al. Metabolomics in prediabetes and diabetes: a systematic review and metaanalysis. Diabetes Care 2016;39(5):833-46.

[8] Wang TJ. Larson MG, Vasan RS, et al. Metabolite profiles and the risk of developing diabetes. Nat Med 2011;17(4):448-53.

[9] Floegel A, Stefan N, Yu Z, et al. Identification of serum metabolites associated with risk of type 2 diabetes using a targeted metabolomic approach. Diabetes 2013;62(2):639-48.

[10] Palmer ND, Stevens RD, Antinozzi PA, et al. Metabolomic profile associated with insulin resistance and conversion to diabetes in the insulin resistance atherosclerosis study. J Clin Endocrinol Metab 2015;100(3):E463-8.

[11] Tillin T, Hughes AD, Wang D, et al. Diabetes risk and amino acid profiles: cross-sectional and prospective analyses of ethnicity, amino acids and diabetes in a South Asian and European cohort from the SABRE (Southall and Brent REvisited) study. Diabetologia 2015;58(5):968-79.

[12] Chen T, Ni Y, Ma X, et al. Branched-chain and aromatic amino acid profiles and diabetes risk in Chinese populations. Sci Rep 2016;6:20594.

[13] Stančáková A, Civelek M, Saleem NK, et al. Hyperglycemia and a common variant of GCKR are associated with the levels of eight amino acids in 9,369 Finnish men. Diabetes 2012;61(7):1895-902.

[14] Wang-Sattler R, Yu Z, Herder C, et al. Novel biomarkers for pre-diabetes identified by metabolomics. Mol Syst Biol 2012;8:615.

[15] Ferrannini E, Natali A, Camastra S, et al. Early metabolic markers of the development of dysglycemia and type 2 diabetes and their physiological significance. Diabetes 2013;62(5):1730-7.

[16] Cheng S, Rhee EP, Larson MG, et al. Metabolite profiling identifies pathways associated with metabolic risk in humans. Circulation 2012;125(18):2222-31.

[17] Henry RJ, Connan DC, Winkelman J. Clinical chemistry. Chap. 25. $2^{\text {nd }}$ edn. Carbohydrates. NY: Harper Row Publishers 1974:1285-9.

[18] Varley H. Practical clinical biochemistry. Chap. 11. $4^{\text {th }}$ edn. Non Protein Nitrogen. New Delhi, India: CBS Publishers 1988:210-2

[19] Legenberg C, Savage DB. An amino acid profile to predict diabetis? Nat Med 2011;17(4):418-20.

[20] Chan S, Akter S, Kuwahara K, et al. Serum amino acid profiles and risk of diabetes among Japnese adults in the hitachi health study. Sci Rep 2019;9(1):7010.

[21] Best JD, Judzewitsch RG, Pfeifer MA, et al. The effect of chronic sulfonylurea therapy on hepatic glucose production in non-insulin dependent diabetes. Diabetes 1982;31(4 Pt 1):333-8.

[22] Campbell PJ, Mandarino LJ, Gerich J. Quantification of the relative impairment in actions of insulin on hepatic glucose production and peripherial glucose uptake in non-insulin dependent diabetes mellitus. Metab Clin Exp 1988;37(1):15-22.

[23] Consoli A, Nurjahan N, Capani F, et al. Predominant role of gluconeogenesis in increased hepatic glucose production in NIDDM. Diabetes 1989;38(5):550-7.

[24] Defronzo R, Gunnarsson R, Bjorkman O, et al. Effects of insulin on peripherial and splanchinic glucose metabolism in noninsulin dependent (type 2) diabetes mellitus. J Clin Invest 1985;76(1):149-55.

[25] Firth RG, BellP M, Marsh HM, et al. Postprandial hyperglycemia in patients with noninsulin-dependent diabetes mellitus. Role of hepatic and extra hepatic tissues. J Clin Invest 1986;77(5):1525-32. 
[26] Gerich J, Mirakou A, Kelley D, et al. Contribution of impaired muscle glucose clearance to reduced post absorptive systemic glucose clearance in NIDDM. Diabetes 1990;39(2):211-6.

[27] Felig P, Marliss E, Cahil GF Jr. Plasma amino acid levels and insulin secretion in obesity. $\mathrm{N}$ Eng $\mathrm{J}$ Med 1969;281(15):811-6.
[28] Hoffman KM, Shah SH, Stevens RD, et al. Relationship between circulating metabolic intermediates and insulin action in over weight to obese inactive men and women. Diabetes Care 2009;32(9):1678-83.

[29] Wurtz P, Soininen P, Kangas AJ, et al. Branched-chain and aromatic amino acids are predictors of insulin resistance in young adults. Diabetes Care 2013;36(3):648-65. 